\title{
Porous structure obtained by anodizing niobium in $\mathrm{NaOH}$
}

\author{
Rafael Martins da Rocha ${ }^{1}$ \\ Leonardo Felix Scheffel ${ }^{1}$ \\ Carlos Leonardo Pandolfo Carone \\ Fernando Dal Pont Morisso ${ }^{1}$ \\ Sandra Raquel Kunst ${ }^{2}$ \\ Jane Zoppas Ferreira ${ }^{2}$ \\ Cláudia Trindade Oliveira ${ }^{1 *}$ (D)
}

\begin{abstract}
Porous structures can be produced as nanotubes, nanowires and membranes, and they can be used in gas sensors, magnetic and electronic devices, biotechnology, etc. These structures can be obtained by the anodizing process, in which the electrolyte must etch the oxide to occur the pore formation. In the case of niobium, porous oxides have been obtained successfully in electrolytes containing hydrofluoric acid (HF). However, studies have shown that niobium dissolves in electrolytes of $\mathrm{NaOH}$ with $\mathrm{pH} 14$, and porous oxides of niobium have already been obtained by the anodizing process with the occurrence of sparking. Thus, the objective of this work is to obtain porous oxides on $\mathrm{Nb}$ without $\mathrm{HF}$ addition by studying the sparking phenomenon. Therefore, niobium was anodized at different current densities $\left(10,25,50,75\right.$ and $\left.100 \mathrm{~mA} . \mathrm{cm}^{-2}\right)$. The samples were evaluated concerning morphology by SEM and chemical microanalysis by EDS. It was observed that sparking depends of the oxide barrier thickness and occurs at current densities higher than $50 \mathrm{~mA} . \mathrm{cm}^{-2}$. However, the increase of the current density, in spite of not increasing the thickness of the barrier layer, caused a greater incidence of sparking. According to the assignment proposed it was possible to obtain a porous structure in niobium with $\mathrm{NaOH}$ electrolyte, but this structure got an irregular aspect.
\end{abstract}

Keywords: Niobium; Anodizing; Porous oxide; Sparking.

\section{Introduction}

Brazil has the major niobium deposits in the world, having $98 \%$ of the metal available in the planet. Also, Brazil is the main niobium producer, with $96 \%$ of the worldwide production. The main deposits are in the states of Minas Gerais, Goiás and Amazonas. Niobium is a metal with high melting point, a slightly higher density than iron, superconductivity at temperatures lower than $-264^{\circ} \mathrm{C}$ and high chemical attack resistance to acids and liquid metals [1]. It is extremely high corrosion resistance and its oxide thermodynamic stability make these materials suitable for a variety of industrial applications [2-4]. The properties of niobium and its oxides have raised large interest that has led to intense research and development [5].

Among the niobium applications, jewelry and nuclear industry use can be mentioned. Also, Niobium is added to titanium to produce superconductor niobium-titanium alloys, used for the magnetic resonance tomography machines magnets. Niobium is also used for electronic ceramic and camera lenses. Niobium anodizing has been carried out to obtain porous oxides employed in gas sensors, catalysts, electrochromic devices, optical fiber, etc. Niobium is a valve metal that shows high oxidation resistance; i.e. it is capable of forming inert oxides that are stable in aqueous medium [6]. Niobium and other valve metals oxides obtained through anodizing grow amorphously until they reach the dielectric breakdown potential and, in consequence, sparking [7]. Niobium anodizing commonly takes place in hydrofluoric acid electrolyte [8], that promotes the formation of pores on the oxides.

Hydrofluoric acid has been widely used to obtain porous structures, which are formed due to the intense dissolution caused by the attack of fluoride ions to the oxide. However, handling hydrofluoric acid can be dangerous, causing irreversible damage to health [9].

There are few studies referring to niobium porous oxides in fluoride-free electrolytes. Some organic electrolytes were already tested $[9,10]$ but the results were not satisfactory when compared to the results of tests conducted with hydrofluoric acid electrolyte.

Literature studies reported that niobium dissolves chemically in $\mathrm{NaOH}$ electrolytes with $\mathrm{pH}=14$. Therefore

${ }^{1}$ Instituto de Ciências Criativas e Tecnológicas - ICCT, Universidade Feevale, Novo Hamburgo, RS, Brasil.

${ }^{2}$ Laboratório de Corrosão, Proteção e Reciclagem de Materiais - LACOR, Universidade Federal do Rio Grande do Sul-UFRGS, Porto Alegre, RS, Brasil.

*Corresponding author: cto@feevale.br

2176-1523 (C) 2021. Rocha et al. Published by ABM. This is an Open Access article distributed under the terms of the Creative Commons Attribution License, which permits unrestricted use, distribution, and reproduction in any medium, provided the original work is properly cited. 
one can expect to promote the formation of porous oxide when using $\mathrm{NaOH}$ electolyte [6].

\section{Materials and methods}

\subsection{Surface preparation}

Before anodizing, niobium samples were cut to the dimensions of $1.5 \mathrm{~cm} \times 1 \mathrm{~cm}$ from a $1 \mathrm{~mm}$ thick commercially pure niobium plate provided by CBMM. After that, all the samples were drilled at one extremity to fix a copper wire as electric contact. Ketone lacquer was applied on the copper contact to avoid it interfere in the anodizing process. The exposed area for all the samples was $2 \mathrm{~cm}^{2}, 1 \mathrm{~cm}^{2}$ in each face.

\subsection{Anodizing}

For anodizing, two platinum $(\mathrm{Pt})$ wire counterelectrodes were used. These electrodes were located parallel and equidistantly from the niobium sample, in order to ensure that the growth of the oxide took place in the same way on both sides of the samples. For this, a non-conductive material device, fixed on the $250 \mathrm{~mL}$ beaker, was used.

Before anodizing, samples was pickled during 10 seconds in $1 \mathrm{M} \mathrm{NaOH}$ solution, heated and stirred. After pickling, samples was washed with deionized water and dried with cold air. Then, the samples were put in between the platinum wires and submersed in the electrolyte. In this process, niobium was the anode, whereas the platinum worked out as cathode. A $300 \mathrm{~V}$ and $0.5 \mathrm{~A}$ power source with a computer assisted data acquisition system was used.

Anodizing process was carried out in galvanostatic mode and with different current densities $(10,25,50,75$ and $100 \mathrm{~mA} . \mathrm{cm}^{-2}$ ), and samples were identified according to Table 1 .

\subsection{Experimental techniques}

\subsubsection{Morphological characterization}

Coatings morphology were evaluated by scanning electron microscopy (SEM), with a Jeol JSM-6510LV equipment. Samples were observed from the top to determine the surface morphology and also in cross sections. Coupled to the SEM equipment, an energy dispersive spectroscopy (EDS) microprobe was used, in order to obtain qualitative information about the chemical composition of the samples.

\section{Results and discussion}

\subsection{Potential transient}

Figure 1 presents a schematic potential transient, where two different regions are observed.

Region 1 shows a linear increase in potential over time, which constant value $(\partial \mathrm{V} / \partial \mathrm{t})$ is named anodizing rate. In this region, there is the formation of a barrier film, in which all the current is used for. $\partial \mathrm{V} / \partial \mathrm{t}$ remains constant until reaching the dielectric breakdown potential or sparking potential $(\mathrm{Vb})$; from which on there is a decrease in the potential increase rate, which starts the Region 2 [7]. Various authors [12-16] reported the behavior transition from Region 1 to Region 2 for some valve metals when anodized, and pointed out that the $(\partial \mathrm{V} / \partial \mathrm{t})$ variation is characteristic of the dielectric breakdown.

During all the different anodizing processes it was observed the presence of small sparks that started on the center of the samples and then went to the surface, with material loss for some samples. This is in agreement with that observed by Ikonopisov [17], since sparking manifests as a chain of individual sparks. Figure 2 shows the potential transients measured during the anodizing processes in $1 \mathrm{M}$

Table 1. Description of the samples: substrate and coating precursor formulation

\begin{tabular}{cc}
\hline Sample & Anodizing conditions \\
\hline $0 \mathrm{Nb}$ & Non-anodized \\
$10 \mathrm{Nb}$ & Anodized with $10 \mathrm{~mA} \cdot \mathrm{cm}^{-2}$ \\
$25 \mathrm{Nb}$ & Anodized with $25 \mathrm{~mA} \cdot \mathrm{cm}^{-2}$ \\
$50 \mathrm{Nb}$ & Anodized with $50 \mathrm{~mA} \cdot \mathrm{cm}^{-2}$ \\
$75 \mathrm{Nb}$ & Anodized with $75 \mathrm{~mA} \cdot \mathrm{cm}^{-2}$ \\
$100 \mathrm{Nb}$ & Anodized with $100 \mathrm{~mA} \cdot \mathrm{cm}^{-2}$ \\
\hline
\end{tabular}

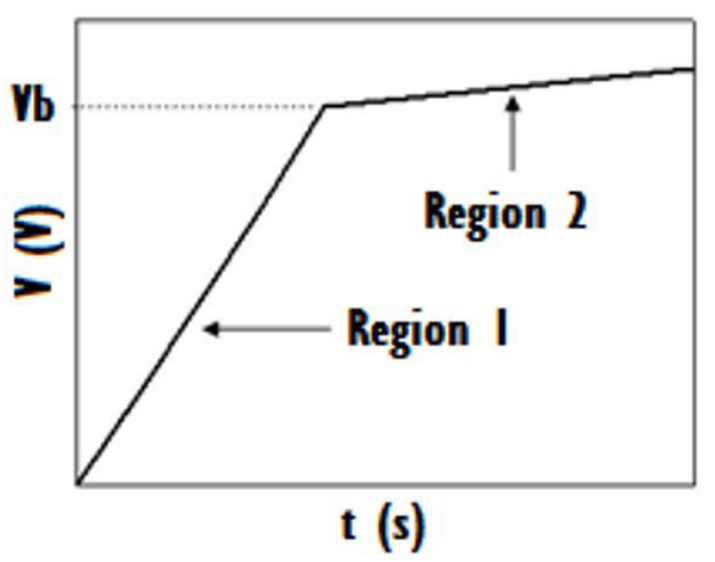

Figure 1. Graphic of the two different regions in the potential transient during niobium anodizing.

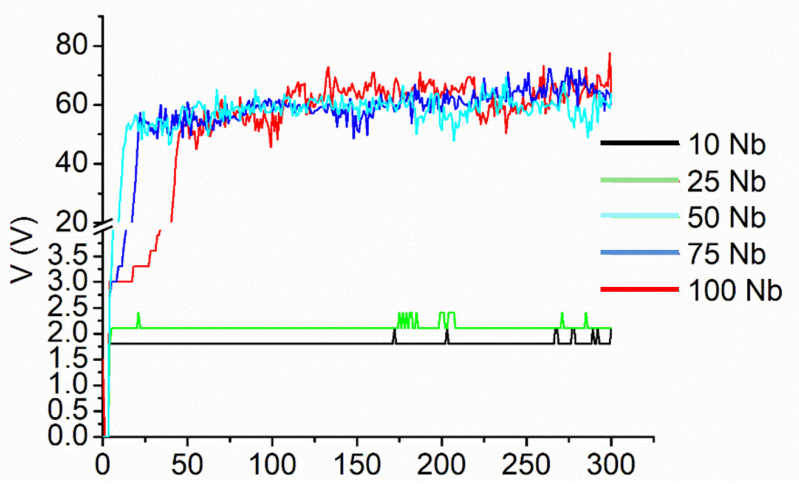

Figure 2. Potential transients for $\mathrm{Nb}$ anodized in 10, 25, 50, 75 and $100 \mathrm{~mA} / \mathrm{cm}^{2}$. 
$\mathrm{NaOH}$ electrolyte. Table 2 gives $(\partial \mathrm{V} / \partial \mathrm{t})$ values measured for the anodized niobium at different current densities.

The sample 10Nb, Figure 2, shows a potential increase up to approximately $2 \mathrm{~V}$ and remains stable. Oliveira [18] anodized niobium under different conditions and found barrier oxide growing rate was independent from the electrolyte. Therefore, the author concluded that the electrolyte did not influence in the oxide layer thickness.

The potential value of $2 \mathrm{~V}$ induces the formation of a low thickness oxide, which can be compared to the behavior of other metal valves such as aluminum, which forms low thickness alumina oxide at low potentials, since the growth of the oxide has an approximate factor of $1.2 \mathrm{~nm} / \mathrm{V}$ [19-21]. The same behavior was verified for titanium with the formation of fine oxide by anodizing at low potentials close to $10 \mathrm{~V}$.

Since $\mathrm{NaOH}$ attacks the base metal, the applied current density could have not been enough to ensure the complete oxide formation, allowing the occurrence of just an attack and dissolution process [8]. Sample 25Nb showed a similar behavior compared to the $10 \mathrm{Nb}$ one. Its final potential was close to $2 \mathrm{~V}$, indicating that there was not an increase in the barrier layer thickness with the increase of the current density until $25 \mathrm{~mA} / \mathrm{cm}^{2}$.

On the other hand, with the increase of current density until $50 \mathrm{~mA} / \mathrm{cm}^{2}$, sample $50 \mathrm{Nb}$ experienced a delay in the start of the anodization process, indicated by the initial time variation up to the potential increase. For the samples $10 \mathrm{Nb}$ and $25 \mathrm{Nb}$, the barrier film has a thickness close to that formed with air exposition; that is why this delay was not seen. It can be observed that the potential increases up to $50 \mathrm{~V}$, indicating the oxide barrier presents a higher thickness. After that, there is a change in the anodizing curve slope, where sparking starts.

Samples $75 \mathrm{Nb}$ and $100 \mathrm{Nb}$ showed a higher potential oscillation after the sparking, in the second part of the curve, which represents that the sparking takes place with the oxide formation, and the phenomenon happened more often than in the other ones.

It was expected that with the increase of current density there were an increase in the oxide thickness, hypothesis that was not proved. It points out that the oxide grows amorphously, until the anodizing rate varies and sparking depends on the potential and the oxide layer thickness.

\subsection{Analysis of the oxides morphology}

Figure 3 presents morphology of the samples with and without anodizing, and Table 3 presents atomic $\%$ of elements obtained by EDS.

Morphology of sample $0 \mathrm{Nb}$ (Figure $3 \mathrm{a}, \mathrm{b}$ ) was evaluated in order to veryfy the electrolyte influence in the sample surface. The surface looks homogeneous, without pores and with some deffects coming from piclking. According
Table 2. Anodizing process results in $1 \mathrm{M} \mathrm{NaOH}$ for different current densities

\begin{tabular}{cccc}
\hline Sample & $\begin{array}{c}\text { Sparking } \\
\text { potential Vb (V) }\end{array}$ & $\begin{array}{c}\text { Time in Region } \\
\mathbf{1}(\mathbf{s})\end{array}$ & $\begin{array}{c}\text { Anodizing rate } \\
\partial \mathbf{V} / \partial \mathbf{t}(\mathbf{V} / \mathbf{s})\end{array}$ \\
\hline $10 \mathrm{Nb}$ & - & 4 & 2 \\
$25 \mathrm{Nb}$ & - & 4 & 2 \\
$50 \mathrm{Nb}$ & 52 & 13 & 7.8 \\
$75 \mathrm{Nb}$ & 54 & 22 & 7.3 \\
$100 \mathrm{Nb}$ & 55 & 46 & 6.8 \\
\hline
\end{tabular}

Table 3. Niobium anodized oxides composition determined by EDS

\begin{tabular}{cccccc}
\hline \multirow{2}{*}{ Sample } & \multicolumn{5}{c}{ Atomic \% } \\
\cline { 2 - 6 } & $\mathbf{O}$ & Al & $\mathbf{C l}$ & $\mathbf{N a}$ & $\mathbf{N b}$ \\
\hline $0 \mathrm{Nb}$ & - & - & - & - & 100.00 \\
$10 \mathrm{Nb}$ & 16.46 & - & - & 0.21 & 83.32 \\
$25 \mathrm{Nb}$ & - & 0.20 & - & - & 99.80 \\
$50 \mathrm{Nb}$ & 32.80 & 0.08 & 0.19 & - & 66.93 \\
$75 \mathrm{Nb}$ & - & 0.23 & - & 32.12 & 67.65 \\
$100 \mathrm{Nb}$ & 57.30 & 0.13 & - & 19.74 & 22.83 \\
\hline
\end{tabular}

to the EDS measurements (Table 3), sodium (Na) was not detected on the surface; proving efficiency of the cleaning process after pickling.

Sample 10Nb micrographs show small deffects on the surface that are apparently similars to the ones on the $0 \mathrm{Nb}$. Table 3 shows a small atomic percent of oxygen, as well as a little significant sodium peak. In this case, it is supposed that an effective sodium incorporation took place. However, it is not possible to state that an oxide was formed, because the anodizing potential was very low, justifying that its thickness, probably, is similar to that formed by air exposition.

The sample $25 \mathrm{Nb}$ surface shows some deffects like those observed on $10 \mathrm{Nb}$. Oxyen or sodium incorporation is not observed in the EDS Table 3. Due to the small dimension of the analyzed region, it is possible that those elements could not be detected, perhaps by the lack of homogeneity of their incorporation on the surface sample.

On the surface of sample $50 \mathrm{Nb}$, irregular shaped pores are present. This is a consequence of the sparking phenomenon. The EDS data in Table 3 shows a significant amount of oxygen and sodium is absent. Regarding D'Alkaine [8], in some cases, the sodium ions precipitate in the electrolytic solution and, that is why, they are not detected by EDS analysis of the surface. Hence, it can be supposed that there was the formation of oxide on the sample surface, even without the confirmation of sodium incorporation.

Samples $75 \mathrm{Nb}$ and $100 \mathrm{Nb}$ show a very porous surface, with irregular shaped pores like those observed in $50 \mathrm{Nb}$. Their EDS data on Table 3 show significant oxygen and sodium amounts.

It was observed that the sparking phenomenon took place with an increasing intensity in the samples $50 \mathrm{Nb}$, $75 \mathrm{Nb}$ and $100 \mathrm{Nb}$. 


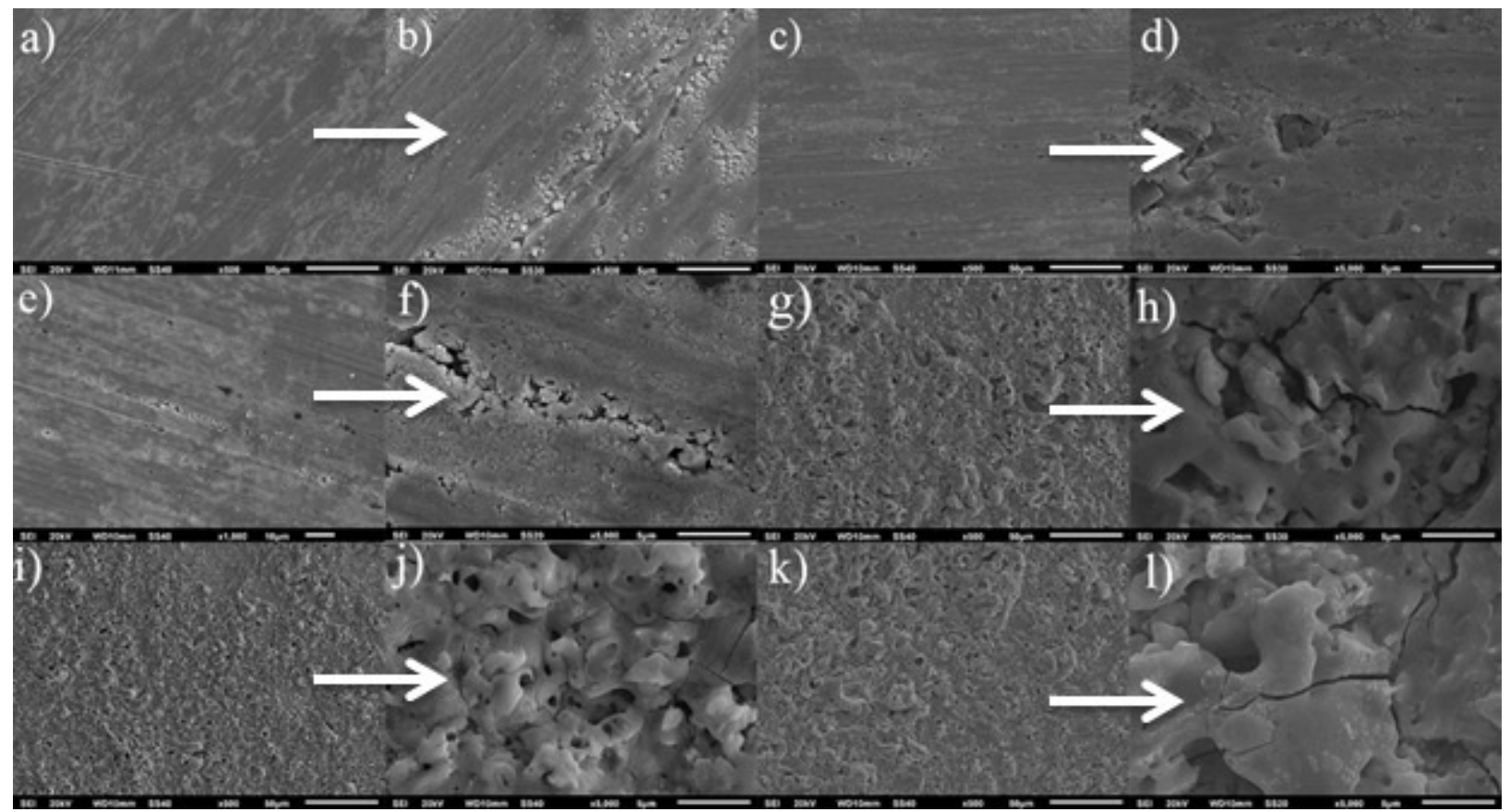

Figure 3. Morphology of the samples with and without anodizing: 500x and 5.000x. (a, b) blank and anodized (c, d) $10 \mathrm{Nb},(\mathrm{e}, \mathrm{f}) 25 \mathrm{Nb}$, $(\mathrm{g}, \mathrm{h}) 50 \mathrm{Nb},(\mathrm{i}, \mathrm{j}) 75 \mathrm{Nb}$ and $(\mathrm{k}, \mathrm{l}) 100 \mathrm{Nb}$.

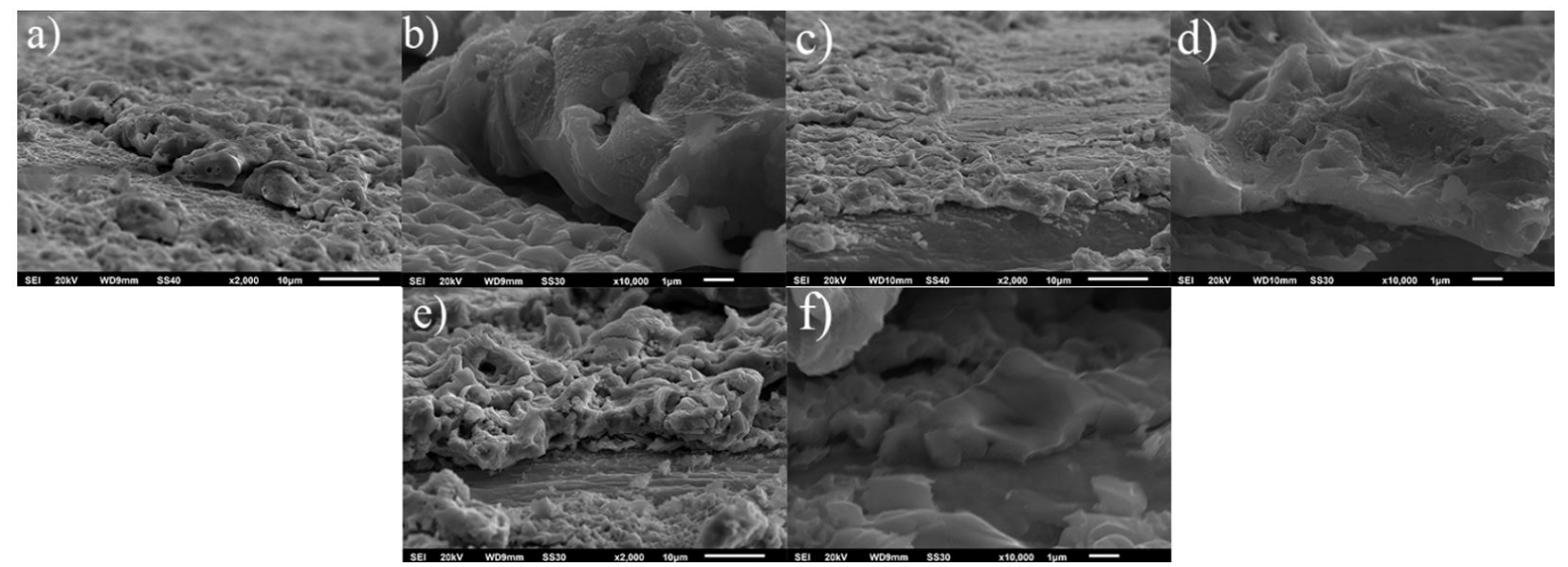

Figure 4. Morphology of cross-section of the anodized samples in different magnifications: 2000x and 10000x: (a, b) $50 \mathrm{Nb}$; (c, d) $75 \mathrm{Nb}$ and $(\mathrm{e}, \mathrm{f}) 100 \mathrm{Nb}$.

\subsection{Cross-section analysis}

Figure 4 shows cross-section of the anodized samples. As aforementioned, it can be stated that samples $10 \mathrm{Nb}$ and $25 \mathrm{Nb}$ formed very thin oxides. That is why cross-section SEM analysis was carried out only for the other samples, which clearly formed niobium oxide. Sample $50 \mathrm{Nb}$ shows an irregular oxide layer, less than $10 \mu \mathrm{m}$ thick. The oxide is cracked due to the sparking phenomenon during the anodization.

Sample $75 \mathrm{Nb}$ presents a similar behavior to that of $50 \mathrm{Nb}$, and it can be perceived irregular oxide formation along the metal surface. However, its oxide layer is thinner than the one in sample $50 \mathrm{Nb}$.

Sample $100 \mathrm{Nb}$ cross-section also shows an irregular oxide formation. This sample presents a higher oxide thickness than the others, consequence of higher sparking incidence that promotes a higher located melting, with irregular morphology.

\section{Conclusion}

It was possible to form oxides when anodizing $\mathrm{Nb}$ in $\mathrm{NaOH}$ at $\mathrm{pH}=14$ when the current density exceeded $50 \mathrm{mAcm}^{-2}$. The oxides formed showed a large incidence pores, randomly distributed, due to the sparking phenomenon. Sparking increased when current density increased.

Based on the obtained results, niobium anodizing with in $1 \mathrm{M} \mathrm{NaOH}$ electrolyte, promotes the formation of porous oxides on the substrate surface. Further studies for obtaining regular porous structure porous structure are needed. 


\section{References}

1 Centro de Estudos e Debates Estratégicos. Minerais estratégicos e terras-raras. Brasília: Edições Câmara; 2014.241 p. (Série Estudos Estratégicos; no. 3).

2 Norlin A, Pan J, Leygraf C. Fabrication of porous Nb2O5 by plasma electrolysis anodization and electrochemical characterization of the oxide. Journal of the Electrochemical Society. 2006;153:B225-B230.

3 Xiao-rong L, Qing-feng D, Yuan-yuan C, Xiao-long R, Shu-rui L, Qing-feng W. Effect of Niobium on dynamic recrystallization behavior of 5\%Ni steel. Journal of Iron and Steel Research International. 2013;20(6):38-44.

4 Rooke JC, Barakat T, Finol MF, Billemont P, Weireldd G, Li Y, et al. Influence of hierarchically porous niobium doped TiO2 supports in the total catalytic oxidation of model VOCs over noble metal nanoparticles. Applied Catalysis B: Environmental. 2013;142-143:149-160.

5 Borcz C, Lepienski CM, Brunatto SF. Surface modification of pure niobium by plasma nitriding. Surface and Coatings Technology. 2013;224:114-119.

6 D'Alkaine CV, Souza LMM, Nart FC. The anodic behavior of Niobium - I. The state of the art. Corrosion Science. 1993;34:109-115.

7 Gomes MAB, Onofre S, Juanto S, Bulhões LO. Anodization of Niobium in sulphuric acid media. Journal of Applied Electrochemistry. 1991;21:1023-1026.

8 D'Alkaine CV, Souza LMM, Nart FC. The anodic behavior of Niobium - II. General experimental electrochemical aspects. Corrosion Science. 1993;34(1):117-127.

9 Vijayan SM, Göen T, Dennerlein K, Horch RE, Ludolph I, Drexler H, et al. Calcium, magnesium and aluminium ions as decontaminating agents against dermal fluoride absorption following hydrofluoric acid exposure. Toxicology In Vitro. 2021;71:105055. http://dx.doi.org/10.1016/j.tiv.2020.105055.

10 Habazaki H, Oikawa Y, Fushimi K, Aoki Y, Shimizu K, Skeldon P, et al. Importance of water content in formation of porous anodic niobium oxide films in hot phosphate-glycerol electrolyte. Electrochimica Acta. 2009;54:946-951.

11 Kirchgeorg R, Wei W, Lee K, So S, Schmuki P. Through-hole, self-ordered nanoporous oxide layers on titanium, niobium and titanium-niobium alloys in aqueous and organic nitrate electrolytes. ChemistryOpen. 2012;1:21-25.

12 Cavigliasso GE, Esplandiu MJ, Macagno VA. Influence of the forming electrolyte on the electrical properties of tantalum and niobium oxide films: an EIS comparative study. Journal of Applied Electrochemistry. 1998;28:1213-1219.

13 Di Quarto F, Piazza S, Sunseri C. Electrical and mechanical breakdown of anodic films on tungsten in aqueous electrolytes. Journal of Electroanalytical Chemistry. 1988;248:99-115.

14 Hornkjol S. Anodic growth of passive films on niobium and tantalum. Electrochimica Acta. 1991;36:1443-1446.

15 Yahalom J, Zahavi J. Experimental evaluation of some electrolytic breakdown hypotheses. Electrochimica Acta. 1971;16:603-607.

16. Marcolin P, Longhi M, Caio L, Zini LP, Beltrami LVR, Silva JC, et al. Obtaining niobium oxides in acetic acid with addition of HF. Tecnolologia em Metalurgia, Materiais e Mineração. 2018;15(1):35-42.

17 Ikonopisov S. Theory of electrical breakdown during formation of barrier anodic films. Electrochimica Acta. 1977;22:1077-1082.

18 Oliveira, C. T. Caracterização microestrutural e Eletroquimica de óxidos de nióbio crescidos por anodização [tese]. Porto Alegre: Programa de Pós-graduação em Engenharia de Minas, Metalúrgica e de Materiais, Escola de Engenharia, Universidade Federal do Rio Grande do Sul; 2007.

19 Baron-Wiecheć A, Burke MG, Hashimoto T, Liu H, Skeldon P, Thompson GE, et al. Tracer study of pore initiation in anodic alumina formed in phosphoric acid. Electrochimica Acta. 2013;113:302-312. http://dx.doi.org/10.1016/j. electacta.2013.09.060.

20 Ma Y, Wen Y, Li J, Li Y, Zhang Z, Feng C, et al. Fabrication of self-ordered alumina films with large interpore distance by janus anodization in citric acid. Scientific Reports. 2016;6(1):1-8. http://dx.doi.org/10.1038/srep39165.

21 Stella K. Electronic dissipation processes during chemical reactions on surfaces. Duisburgo-essen: Disserta Verlag; 2011. $256 \mathrm{p}$.

Received: 7 Mar. 2019

Accepted: 5 Nov. 2020 